\title{
DYADIC GOVERNANCE: JOINT TRUST, TRUST ASYMMETRY, AND EXCHANGE PERFORMANCE
}

\author{
MENGYANG WANG \\ School of Business \\ The University of Hong Kong, Hong Kong \\ K.K.Leung Building, Pokfulam Road, Hong Kong
}

KEVIN ZHENG ZHOU

The University of Hong Kong, Hong Kong

\section{INTRODUCTION}

Trust is a focal construct in buyer-supplier exchanges, yet prior literature has not paid adequate attention to its asymmetric nature (De Jong \& Dirks, 2012; Zaheer \& Zaheer, 2006). Because trust is dyadic, buyers and suppliers often develop different trust perceptions of their partners, and asymmetric trust thus is a reality in interfirm exchanges (Svensson, 2006). Most empirical studies overlook this asymmetry though (Graebner, 2009; Poppo, Zhou, \& Li, 2016), instead relying on unilateral trust, such as buyer trust (Gulati \& Sytch, 2007) or supplier trust (Dyer \& Chu, 2000; Sako \& Helper, 1998) to assess interfirm trust. Under-developed is how asymmetric trust affects exchange outcomes in interfirm exchanges.

Furthermore, trust is subject to boundary conditions; although prior work recognizes that its performance impact depends on transactional characteristics, extant empirical findings are mixed (Poppo et al., 2016). For example, using buyer-side perceptions, Poppo, Zhou, and Zenger (2008) show that the positive impact of trust-based relational governance on exchange performance is weaker at high levels of asset specificity. In contrast, using supplier-side trust perceptions, Aulakh, Kotabe, and Sahay (1996) reveal that the potential opportunism involved in high asset specificity makes the role of trust more important for safeguarding transactions.

These inconclusive findings might result from a failure to take trust asymmetry into consideration. Therefore, we distinguish two aspects of interfirm trust: joint trust and trust asymmetry. We accordingly examine how joint trust and buyer trust asymmetry affect exchange performance differentially, while also assessing the contingent roles of transactional attributes: asset specificity (AS) and supply market uncertainty.

This study contributes to existing research in several ways. First, we empirically examine trust asymmetry in buyer-supplier relationships, responding to a long-standing call in trust literature (Zaheer \& Harris, 2005). By differentiating buyers' and suppliers' roles, our consideration of trust asymmetry helps explain why interfirm trust does not work in some cases (Dyer \& Chu, 2003; Zaheer \& Harris, 2005). Second, we reveal that joint trust and buyer trust asymmetry perform differentially across different levels of transactional attributes, and help explain prior inconsistency (Krishnan, Martin, \& Noorderhaven, 2006; Poppo et al., 2008). Overall, we contribute to extant trust research by highlighting the bilateral and asymmetric nature of trust.

\section{THEORETICAL FRAMEWORK}

\section{Trust asymmetry and joint trust}


Relational exchange theory emphasizes that social relations play a critical role in economic exchanges, because all exchanges are embedded in social environments (Macneil, 1980). One of the most fundamental social relations is trust, or a belief in the exchange partner's reliability, benevolence, and integrity (Zaheer, McEvily, \& Perrone, 1998). Trust breeds positive beliefs about collective interests, encourages exchange parties to share information and resources, allows for flexibility in coordinating, leading to better performance (Dyer \& Chu, 2003). Most extant literature, however, uses unilateral trust to represent interfirm trust but overlooks the potential divergence between exchange parties (Graebner, 2009). Thus, we consider two facets of interfirm trust simultaneously: joint trust and trust asymmetry (De Jong \& Dirks, 2012). Joint trust refers to the overall strength of the trusting relationship (i.e., buyer trust plus supplier trust); trust asymmetry reflects the gap between exchange partners in their trust perceptions (De Jong \& Dirks, 2012). In this study, we focus on buyer trust asymmetry (i.e., buyer trust minus supplier trust), because in modern markets, buyers usually initiate and lead transactions (Pedersen \& Andersen, 2006).

\section{Transactional attributes}

The effect of trust is conditional on transactional attributes (Poppo et al., 2016). According to transaction cost economics, asset specificity and market uncertainty are two salient attributes that increase transaction costs and exchange hazards (David \& Han, 2004; Williamson, 1985). Asset specificity (AS) refers to unique, non-redeployable transaction investments in the relationship (Williamson, 1985). Both buyers and suppliers can make specific investments, so we consider both joint AS and buyer AS asymmetry. Joint $A S$ is the sum of transaction-specific assets contributed by both buyers and suppliers to the relationship (Bercovitz, Jap, \& Nickerson, 2006). Buyer AS asymmetry measures buyer-specific assets minus supplier-specific assets. Market uncertainty refers to the degree of unanticipated changes in external environments surrounding the exchange (Williamson, 1985). It increases transactional risk and coordination costs, leading to an adaption problem (Rindfleisch \& Heide, 1997). Following prior studies in buyer-supplier exchanges (e.g., Cannon \& Perreault, 1999), we focus on supply market uncertainty, which assesses the fluctuations of pricing, product features, and product amounts in the supply market.

\section{HYPOTHESES}

\section{Direct effects of joint trust and trust asymmetry}

The positive effect of mutual trust on exchange performance is well documented in existing literature (Zaheer et al., 1998). Joint trust makes exchange parties more willing to share confidential information and critical resources within the relationship, due to their low perceived risk (Dyer \& Chu, 2003). Information sharing helps partners resolve potential problems and accomplish their goals efficiently (Dyer \& Chu, 2003). Furthermore, with high mutual trust, the business partners hold shared positive expectations about the relationship's continuity (Doney \& Cannon, 1997). This makes partners show more flexibility and make mutual adaptations to coordinate, which reduces transactional conflicts and fosters performance (Dyer \& Chu, 2003).

\section{Hypothesis 1a: Joint trust is positively associated with exchange performance.}

When buyers hold more trust than suppliers, the asymmetry may lead to negative outcomes. First, less-trusting suppliers commit less to the relationship. Information about component quality, 
specifications, and costs is critical for buyers to plan their own production, but such confidential information is owned exclusively by suppliers (Sako \& Helper, 1998). Without these details, buyers cannot identify potential issues or ensure that their final products will match well with the supplied components. Thus, the information asymmetry is detrimental to exchange performance. Second, there is more scope for suppliers to engage in opportunism. To constrain opportunism, buyers often monitor their partner's behaviors and output (Heide \& Wathne, 2006), but if the buyers are trusting more, they promise more flexibility and spend less time monitoring (Dyer \& $\mathrm{Chu}, 2003$ ), which creates space for the suppliers to behave opportunistically (e.g., deliver lowquality products). If suppliers provide products with hidden defects, it is both costly and unrealistic for buyers that lack specific component knowledge to identify.

In contrast, if suppliers trust more, they likely provide important component information (Dyer \& Chu, 2003), which enables buyers to plan and adapt better. Also, trusting suppliers are willing to accomplish their production tasks well, which is critical to exchange success (Whipple \& Roh, 2010). In such conditions, buyers may express less trust, but they still must provide specific information to suppliers to accomplish their tasks. Also, compared with supplier opportunism, buyer opportunism (e.g., payment delays) is easier to identify (Joshi \& Arnold, 1997). Accordingly, suppliers' higher trust has a limited effect on buyers' motivation to behave opportunistically.

\section{Hypothesis 1b: Buyer trust asymmetry is negatively associated with exchange performance.}

\section{Moderating effects of transactional attributes}

Joint asset specificity. Joint AS, or the degree of mutual customized exchanges, indicates interdependent sunk costs (Williamson, 1985). When partners make highly specialized investments, they must share extensive information to ensure efficient coordination (Narayanan, Narasimhan, \& Schoenherr, 2015). By promoting bilateral sharing, joint trust enables partners to exploit their specialized assets fully and enhances performance. Moreover, the flexibility created by joint trust becomes more important in highly specified exchanges. High joint AS requires partners to work closely to utilize such specialized investments, which increases the need for continuous adaptations and flexibility (Poppo et al., 2016). By indicating that partners will not appropriate efforts, joint trust facilitates flexible adaptation and integrated collaboration (Zhou \& Poppo, 2010), which help exchange partners realize the value of their specific investments.

\section{Hypothesis 2a: The relationship between joint trust and exchange performance is more positive when joint AS is high than when it is low.}

The supplier, which controls the production process and component quality, must engage in active information sharing to leverage specialized resources and achieve mutual gains (Mesquita $\&$ Brush, 2008). If suppliers trust less, they are unlikely to engage in such active information sharing, which creates significant barriers to improve the exchange through idiosyncratic investments (Dyer \& Singh, 1998). As a result, buyer trust asymmetry likely leads to the misuse of mutual investments. Moreover, joint AS makes the threat of supplier opportunism more evident. Because suppliers control production, their role is especially critical for using the specialized assets to generate value (Buvik \& Reve, 2001). If buyers trust less, they pay more attention to ensure that suppliers do not shirk; if suppliers trust more, they share information and perform well. However, if suppliers trust less, they likely misappropriate the considerable specialized investments in high joint AS settings. 
Hypothesis 2b: The relationship between buyer trust asymmetry and exchange performance is more negative when joint AS is high than when it is low.

Buyer asset specificity asymmetry. When buyers invest more specialized assets, they tailor their operations or product designs to the suppliers' components or routines (Buvik \& Reve, 2001). Detailed information about supplier components then is critical to help buyers make these matches and facilitate their production (Narayanan et al., 2015). Joint trust is especially helpful for promoting the supplier's information sharing and supporting buyers' efforts to arrange their own production. Moreover, when buyer AS asymmetry is high, buyers face high sunk costs that limit their ability to switch suppliers (Mesquita \& Brush, 2008). Because joint trust provides exchange parties with shared identities and beliefs about their collective interests, it transforms buyer AS asymmetry into a credible commitment, rather than an exploitation opportunity for suppliers (Poppo et al., 2016; Zaheer et al., 1998). Then the exchange partners can make good use of their specialized assets to reduce exchange costs and promote exchange performance.

Hypothesis 3a: The relationship between joint trust and exchange performance is more positive when buyer AS asymmetry is high than when it is low.

High buyer AS asymmetry intensifies the negative relationship between buyer trust asymmetry and exchange performance. First, with high buyer AS asymmetry, buyers would offer more specific information with their relatively higher investments, exacerbating the information gap between buyers and suppliers. With limited information from suppliers, buyers cannot match their investment with the supplied components or arrange their own operation (Mesquita \& Brush, 2008). Second, high buyer AS asymmetry encourages less-trusting suppliers to pursue their selfinterest, with higher returns and lower risk. The trusting buyers have higher sunk costs, so it would be difficult for them to punish the suppliers or terminate the relationship (Stump \& Heide, 1996).

Hypothesis 3b: The relationship between buyer trust asymmetry and exchange performance is more negative when buyer AS asymmetry is high than when it is low.

Supply market uncertainty. Under high supply market uncertainty, joint trust becomes more important for promoting exchange performance. When they face greater uncertainty, exchange parties turn to reliable partners for valid information and resources (Li, Poppo, \& Zhou, 2008). Joint trust enables them to obtain critical information and exclusive resources from partners, such that they can respond better to market changes ( $\mathrm{Li}$ et al., 2008). Market uncertainty also requires exchange partners to make quick, continuous adaptations (Li, Poppo, \& Zhou, 2010). If they enjoy joint trust, partners make timely adjustments and resolve issues flexibly, such that they react to unforeseen changes effectively (Poppo et al., 2016). For example, through integrative coordination, suppliers can make proper adjustments to their inventory to meet unexpected contingencies.

Hypothesis 4a: The relationship between joint trust and exchange performance is more positive when supply market uncertainty is high than when it is low.

Buyer trust asymmetry also becomes more detrimental with high supply market uncertainty. First, in fluctuating markets, suppliers must provide up-to-date, accurate information for buyers to deal effectively with external changes (Nyaga, Whipple, \& Lynch, 2010). However, if suppliers express less trust, they tend to withhold this information. Without the crucial information, buyers 
cannot make appropriate adjustments. Second, when supply market uncertainty is high, moretrusting buyers likely attribute potential problems to the external environment rather than the suppliers. Suppliers in turn could exploit this trust to pursue their self-interest and reduce their efforts to foster performance (Srinivasan, Mukherjee, \& Gaur, 2011). In contrast, when market uncertainty is low, there are no alternative excuses, which should help curtail supplier opportunism.

Hypothesis 4b: The relationship between buyer trust asymmetry and exchange performance is more negative when supply market uncertainty is high than when it is low.

\section{METHODS}

\section{Sampling and data collection}

We gathered dyadic data about buyer-supplier relationships from manufacturing firms in China. For each firm, we identified a senior purchasing manager in charge of supplier management as a key informant. We asked each informant to select a primary supplier and assess this specific, ongoing relationship. With this referral, we contacted these supplier managers to obtain their assessments of the exchange relationships. We collected a usable sample of 432 buyer-supplier dyads, for an effective response rate of $36 \%$. To assess the causal link between trust and performance, we collected data in two waves. This reduces the potential for endogeneity and common method variance (Podsakoff, MacKenzie, Lee, \& Podsakoff, 2003). The second wave results in 250 matched responses. After deleting 15 dyads with missing data, the final sample includes 235 matched responses across the two periods (54.4\% of the dyads from Wave 1$)$. We found no significant differences in firm size, age, or ownership between the samples of two waves.

\section{Measures}

We developed multi-item scales for the focal variables, on the basis of prior research and our fieldwork. We assessed buyer trust and supplier trust with three items adapted from Zaheer et al. (1998). Joint trust was calculated as the sum of buyer trust and supplier trust. Buyer trust asymmetry was measured as buyer trust minus supplier trust. The three items to measure asset specificity came from Cannon and Perreault (1999). We obtained these evaluations from both the buyer and supplier sides. We then calculated joint $A S$ as the sum of buyer AS plus supplier AS and buyer AS asymmetry as buyer AS minus supplier AS. We adapted a scale from Cannon and Perreault (1999) to measure supply market uncertainty. This information was collected from suppliers. Exchange performance relied on a four-item scale adapted from Bercovitz et al. (2006) that assesses relationship performance. We calculated the average between the buyer and supplier evaluations to indicate exchange performance.

Because we collected this information in Wave 2, we could test the causal link between trust and performance. As control variables, we included exchange duration, procurement concentration, buyer/supplier age, buyer/supplier sales, and buyer industry types; these data were collected in Wave 1. The information for these control variables mostly came from the buyer side, except for firm age and sales, which included both sides.

We conducted confirmatory factor analysis to assess the fit of our measures (Anderson \& Gerbing, 1988). The model shows a satisfactory fit (chi-square/degrees of freedom $=2.68$, RMSEA $=0.08, \mathrm{CFI}=0.95$, IFI=0.95). Measures also indicate adequate convergent validity and reliability (Bagozzi \& Yi, 1988), and discriminant validity (Koufteros, 1999). Our longitudinal 
design and multiple sources limit concerns of common method variance. By collecting data from both buyers and suppliers, we also reduce the potential for common method bias due to singlesource information (Podsakoff et al., 2003).

\section{ANALYSES AND RESULTS}

Following Slotegraaf, Moorman, and Inman (2003), we adopted a two-stage regression analysis to handle this potential endogeneity. The results indicate that joint trust enhances exchange performance $(\mathrm{b}=0.28, p=0.00)$, and buyer trust asymmetry negatively affects it $(\mathrm{b}=-0.14, p=$ $0.03)$. This support for H1a and H1b. The positive interaction between joint AS and joint trust $(\mathrm{b}=$ $0.17, p=0.01$ ) supports H2a. However, the interaction between joint AS and buyer trust asymmetry is not significant $(b=-0.11, p=0.11)$, so we cannot confirm $\mathrm{H} 2 \mathrm{~b}$. The interaction effect of joint trust and buyer AS asymmetry is significantly positive $(\mathrm{b}=0.14, p=0.03)$, in support of $\mathrm{H} 3 \mathrm{a}$. Moreover, the interaction of buyer trust asymmetry and buyer AS asymmetry is significantly negative $(\mathrm{b}=-0.12, p=0.05)$, which lends support to $\mathrm{H} 3 \mathrm{~b}$. Consistent with our prediction in $\mathrm{H} 4 \mathrm{a}$, supply market uncertainty positively moderates the effect of joint trust on exchange performance $(b$ $=0.14, p=0.04$ ). Also consistent with $\mathrm{H} 4 \mathrm{~b}$, the interaction between buyer trust asymmetry and supply market uncertainty is significantly negative $(\mathrm{b}=-0.20, p=0.00)$.

\section{DISCUSSION}

\section{Research implications}

We adopt a dyadic view of trust to explicate the different implications of joint trust and buyer trust asymmetry for exchange performance. Our study represents important contributions to existing trust literature. First, we enrich extant research by undertaking a dyadic analysis that uncovers the dark side of trust asymmetry. By distinguishing between joint trust and trust asymmetry, we offer new insights into how interfirm trust functions. Compared with buyer trust, supplier trust is especially valuable for exchanges, due to the proprietary information that suppliers possess and the difficulty associated with identifying supplier opportunism. Our findings show that trust asymmetry represents an important determinant of negative exchange performance in buyersupplier relationships.

Second, our study adds nuance to the understanding of the boundary conditions of interfirm trust (Poppo et al., 2016). High joint AS augments the strength of joint trust in promoting exchange performance; by facilitating information sharing and efficient coordination, joint trust enables the extensive use of specific assets to create value. Prior studies show that trust can have a stronger (Aulakh et al., 1996) or weaker (Poppo et al., 2008) effect on performance when AS is high. Our findings offer fresh insights: this inconsistency arises not only from the different sides (i.e., buyer or supplier) but also from whether buyer and supplier AS is symmetric or not. Facing high supply market uncertainty, exchange parties with joint trust can share information quickly and make timely adaptations, whereas relationships marked by buyer trust asymmetry suffer more. These findings help reconcile contradictory findings regarding supply market uncertainty as a boundary condition of trust. Overall, considering both joint and asymmetric trust provides a more complete explanation of the role of trust and its boundary conditions.

\section{REFERENCES AVAILABLE FROM THE AUTHOR(S)}


Copyright of Academy of Management Annual Meeting Proceedings is the property of Academy of Management and its content may not be copied or emailed to multiple sites or posted to a listserv without the copyright holder's express written permission. However, users may print, download, or email articles for individual use. 